\title{
A Nudge in a Healthier Direction: \\ How Environmental Cues Help Restrained Eaters \\ Pursue Their Weight-Control Goal
}

Losing weight is a goal for many people, but it is hard to pursue. However, dieting cues in the environment hold promise for improving individuals' eating behavior. For example, exposure to thin, human-like sculptures by the artist Alberto Giacometti has been found to promote healthy snack choices at a vending machine. Whether health- or weight-related processes drive such effects has not yet been determined. However, a detailed understanding of the content-related drivers of environmental cues' effects provides the first indications regarding a cue's possible use. Therefore, two laboratory studies were conducted to examine the Giacometti sculptures' effects on unhealthy and healthy food intake (Study 1) and on the completion of weight- and health-related fragmented words (Study 2). Study 1 indicated that the sculptures are weight-related by showing that they reduced food intake independent of food healthiness. Furthermore, the "Giacometti effect" was moderated by restrained eating. Restrained eaters, who are known for their weight-control goal, ate less after having been exposed to the thin sculptures. The results of Study 2 pointed in the same direction. Restrained eaters completed more weight-related words after being exposed to the sculptures. Overall, these studies suggest that the thin sculptures are primarily weight-related cues and particularly helpful for restrained eaters. Environmental weight-control cues such as the Giacometti sculptures could act as a counterforce to our obesogenic environment and help restrained eaters pursue their weight-control goal. In this way, they could nudge food decisions in a healthier direction.

Keywords: environmental cue; restrained eating; weight-control goal; dieting; nudging 
A Nudge in a Healthier Direction: How Environmental Cues Help Restrained Eaters Pursue Their Weight-Control Goal

We eat what we eat particularly because we like it (Renner, Sproesser, Strohbach, \& Schupp, 2012). In our "obesogenic" environment, with its abundance of tasty, high-calorie food, our goal of eating enjoyment gets constantly activated. As a result, we eat too much energy-dense food (Berthoud, 2006; Papies, 2016; Papies, Potjes, Keesman, Schwinghammer, \& van Koningsbruggen, 2014; Renner et al., 2012), which in turn contributes to the global obesity epidemic (World Health Organization, 2016). However, just as the obesogenic environment fosters unhealthy eating, the environment can also foster healthy eating. For example, dieting cues in a restaurant menu stimulate the choice of low-calorie dishes (Papies \& Veling, 2013). Such environmental cues are thought to activate weight-control or health goals (Papies, 2016).

An environmental cue that has repeatedly been found to foster healthy eating is the thin, human-like sculptures by the artist Alberto Giacometti. Exposure to these sculptures made healthy snack choices at a vending machine more likely (Stöckli, Stämpfli, Messner, \& Brunner, 2016) and reduced the intake of unhealthy, high-calorie chocolate and chips (Brunner \& Siegrist, 2012; Stämpfli \& Brunner, 2016). However, it is uncertain which goal primarily drives this "Giacometti effect," as both a health and a weight-control goal are conceivable drivers. This ambiguity reflects the state of the literature on environmental cues. Despite manifold empirical evidence on the effects of environmental cues, the understanding of the specific semantic content activated by a cue is often not revealed (Bargh, 2006; e.g., Papies \& Veling, 2013). A detailed understanding of the semantic content activated by a cue and thus driving a cue's effects would be a first indication regarding a cue's possible purpose. Therefore, the goal of the 
present research was to identify the semantic content that is activated by the Giacometti cue.

\section{Environmental Cues Prime Healthy Eating}

When cues in the environment influence eating behavior, they act as primes. Normally, individuals are not aware of being primed (Bargh, Gollwitzer, Lee-Chai, Barndollar, \& Trötschel, 2001; Chartrand, 2005). Primes unconsciously and temporarily activate semantically associated mental content that is then more likely integrated into ongoing mental processes and, more likely, influences behavior (Bargh et al., 2001; Bargh, 2006; Janiszewski \& Wyer, 2014; Jones \& Estes, 2012).

Goals are a specific type of mental content that can be activated (Aarts, 2007; Janiszewski \& Wyer, 2014). Due to their motivating capacity (Custers \& Aarts, 2005), goals are important drivers for priming effects (Aarts, 2007). For example, individuals with the goal of visiting a library spoke more quietly after being exposed to a picture of a library, compared to when they only saw the picture but did not have the goal in mind (Aarts \& Dijksterhuis, 2003). Thus, regarding the Giacometti cue, it is important to determine not only whether the thin sculptures are primarily associated with weight or health, but also whether individuals have a weight-control or health goal in mind.

As mental content is embedded in an associative network, the activation of mental content spreads to associated contents (Aarts, 2007; Janiszewski \& Wyer, 2014; Jones \& Estes, 2012). In this way, activated weight-related content could activate health-related content. However, in the specific case of goals, it is difficult to predict how weight-control and health goals would interact with each other. On the one hand, they could facilitate each other when they serve as means to each other's attainment. On the other hand, they could inhibit each other when they are perceived as substitutive for an overarching purpose (Shah, Friedman, \& Kruglanski, 2002). 
When environmental cues are applied for public policy purposes - to improve public health, for example_ priming is termed "nudging." Nudging means guiding people toward the interest of society as well as toward self-interested behavior by arranging the decision-making context (Thaler \& Sunstein, 2009). Thus, the important role of personal goals for priming effects fits with the notion of nudging.

\section{Environmental Dieting Cues Particularly Affect Restrained Eaters}

Given the obesity epidemic (World Health Organization, 2016) and the societal ideal of thinness (van de Veer, van Herpen, \& van Trijp, 2015), dieting is a goal for many people. Individuals with a chronic goal of weight control are referred to as “restrained eaters” (Herman \& Mack, 1975; Stroebe, Mensink, Aarts, Schut, \& Kruglanski, 2008). Although restrained eating has been conceptualized as an eating behavior independent of individuals' weight (Herman \& Mack, 1975; Herman \& Polivy, 1980; van Strien, Breteler, \& Ouwens, 2002), restrained eating has repeatedly been found to correlate positively with body mass index (Snoek, Engels, van Strien, \& Otten, 2013; van Koningsbruggen, Stroebe, \& Aarts, 2011).

Paradoxically, restrained eating does not predict weight loss, but rather weight gain (Lowe, Doshi, Katterman, \& Feig, 2013). This can be attributed to our obesogenic environment (Papies et al., 2014) in combination with the goal of eating enjoyment, by which restrained eaters are characterized as well (Stroebe et al., 2008; Stroebe, van Koningsbruggen, Papies, \& Aarts, 2012). The fragile balance between restrained eaters' conflicting goals of weight control and eating enjoyment (Stroebe et al., 2008, 2012) makes them particularly sensitive to food-related cues (Fedoroff, Polivy, \& Herman, 1997, 2003; Hofmann, van Koningsbruggen, Stroebe, Ramanathan, \& Aarts, 2010; Papies, Stroebe, \& Aarts, 2008; Soetens, Roets, \& Raes, 2014), but, promisingly, also to dieting-related cues in the environment (Anschutz, van Strien, \& Engels, 2008; Harris, 
Bargh, \& Brownell, 2009; Papies \& Hamstra, 2010; Papies \& Veling, 2013; Versluis \& Papies, 2016). Thus, the influence of the Giacometti sculptures on restrained eaters can provide important insight into whether the cue is driven by a weight-related goal.

\section{The Present Research: Thin, Human-Like Sculptures as an Environmental Health or Weight-Related Cue}

To examine whether the Giacometti effect is driven primarily by weight- or health-related mental content, Study 1 analyzes the sculptures' effects on the consumption volume of unhealthy and healthy foods by applying a between-subjects design. If the sculptures are primarily weight-related, it is hypothesized that being exposed to them will lead to participants' reduced food intake independent of food healthiness. This is because the goal of weight control, and thus calorie reduction, should drive the effect. In this case, no interaction is expected between the cue and food healthiness, but a main effect of the cue on food intake is expected. If the cue is primarily health-related, a health goal should drive the effect. It is hypothesized that in this case, exposure to the sculptures not only will inhibit the intake of unhealthy foods, but will also facilitate the intake of healthy foods, as these are thought to improve one's health. This is because individuals in our sample should be aware of the prevailing insufficient intake of fruits and vegetables, due, for example, to the nationally-known health campaign "5 a day" in Switzerland (Cancer League Switzerland, 2016). They may also know the negative health consequences related to the insufficient intake of fruits and vegetables, such as heart diseases (World Health Organization, 2002, 2004). Thus, an interaction between the cue and food healthiness is expected if the cue is primarily health-related.

Study 2 directly examines the activation of weight- or health-related mental content by means of a word completion task. While the cue's effect on the completion 
of weight-related words should be facilitated by a weight-control goal, the cue's effect on the completion of health-related words should be facilitated by a health goal. In addition, the correlations of weight- and health-related word completions in the cue and the no-cue condition are compared to discern the interplay of the potentially activated weight-control or health goals.

\section{Study 1: The Influence of Thin Sculptures on Unhealthy and Healthy Food Intake}

\section{Method}

Participants. Members of a sensory consumer panel and employees and students of a university were invited personally or via e-mail for a food tasting on campus. The tasting objects were not disclosed to ensure that weight-control or health goals did not influence the registrations. Potential participants could choose an appointment on one of seven days between 8:00 a.m. and 18:00 p.m. No appointments were made between 12:00 and 14:00 p.m. in order to circumvent lunchtime influences. Individuals who had participated in a previous study using the Giacometti cue were excluded.

One hundred and thirty-three individuals participated in the study. As they were accustomed, the members of the consumer panel received a compensation of 25 Swiss Francs and the employees and students received a compensation of 10 Swiss Francs. The data of 133 participants were collected. The data of 114 participants were used for the analyses $\left(M_{\text {age }}=31.72\right.$ years, $S D_{\text {age }}=14.11 ; 61.95 \%$ female $)$. Eighteen participants were excluded from the analyses because they stated that they had heard of the study before and therefore had an idea about the study's purpose, and one participant was excluded because of a missing value for this question.

Design. A 2 (cue vs. no cue) $\times 2$ (unhealthy vs. healthy food) between-subjects design was applied to examine the cue's influence on consumption volume. 


\section{Materials and measures.}

Cue. The Giacometti screensaver in the cue condition showed an extract of a photograph depicting three thin figures from Giacometti's sculpture Piazza $a^{1}$ moving in front of a black background (Brunner \& Siegrist, 2012; Stämpfli \& Brunner, 2016).

Food. Each participant was given either 20 chocolates in the unhealthy condition $\left(M_{\text {weight }}=45.21, S D_{\text {weight }}=1.32\right)$ or 20 blueberries in the healthy condition $\left(M_{\text {weight }}=39.02, S D_{\text {weight }}=4.68\right)$. The chocolates consisted of milk chocolate with a crunchy core. Care was taken to ensure that the blueberries were similar in size to the chocolates.

Measures. The main dependent variable of this study, consumption volume, was captured by weighing the blueberries or chocolates in a small plastic bowl before and after the tasting and calculating the weight difference. To measure whether participants had a weight-control goal, Restrained eating ( $\alpha=.71$ ) was captured with the German version (Dinkel, Berth, Exner, Rief, \& Balck, 2005) of the Concern for Dieting subscale of the Revised Restraint Scale (Herman \& Polivy, 1980). Comprising six items, this subscale has proven to capture restrained eating better than the entire restraint scale (van Strien et al., 2002). Example items are "How often are you dieting?"; "Do you give too much time and thought to food?"; and "Do you have feelings of guilt after overeating?" These were captured on 7-point Likert scales $(1=\mathrm{I}$ do not agree at all; $7=\mathrm{I}$ entirely agree). For the purpose of ensuring that we created a healthy and an unhealthy condition, the question "In your opinion, how healthy was the product which you have tasted?" was answered at the end of the study on a 7-point Likert scale $(1=$ Very unhealthy; 7 = Very healthy).

\footnotetext{
${ }^{1}$ This sculpture can be found using Google's image search for "Giacometti Piazza."
} 
To assess participants' suspicion about the study purpose, they were asked:

"Have you heard about this study and therefore have an idea what the purpose of the study is?" To rate the foods and to answer further questions, participants completed a computer-based questionnaire generated with E-Prime, version 2.0.10.353 (E-Prime 2 Professional).

Procedure. In the cue condition, participants entered the experimental room while a screensaver with thin, human-like sculptures by the artist Alberto Giacometti, running on the experimenter's laptop computer, was projected on a screen. Participants in the no-cue condition entered the experimental room when the experimenter's laptop computer was closed. This way, the projection screen was lit in blue.

The experimental room was a computer room with tiers, a projection screen, and a high desk in front. The computers used for the data collection were separated by partitions to build cubicles. First, participants were asked to come to the front tier to receive oral instructions from the experimenter. No partitions were installed in this first tier to ensure that all participants could see the screen. The direct exposure to the screen during the instructions took about 30 seconds. Afterward, participants chose a seat and the experimenter or a study assistant served the food samples for the tasting. Either chocolates or blueberries were served for each group. Then, participants had 5 minutes to taste and rate the chocolates or blueberries. They were instructed to eat as much as they wanted. After the food samples were distributed, the experimenter switched off the projector. After the tasting, participants completed the questionnaire.

\section{Results}

Manipulation check. The creation of a healthy and an unhealthy condition with chocolates and blueberries was successful. Participants rated the food samples to be 
healthier when they tasted blueberries $(M=5.77, S D=1.33)$ than when they tasted chocolates $(M=2.74, S D=1.25), t(111)=12.48, p<.01, d=2.35$.

Unspecific "Giacometti effect." With a two-factor ANOVA, the cue's effect on participants' consumption volume of unhealthy and healthy foods was examined. The analysis revealed that the projected Giacometti screensaver influenced how much food participants ate, $F(1,110)=3.96, p<.05, \eta^{2}=.03$. The participants who had been exposed to the projected Giacometti screensaver ate less $(M=17.83$ grams, $S D=9.68)$ than the participants who had been exposed to the neutral blue projection screen $(M=$ 21.82 grams, $S D=10.81), t(112)=2.08, p=.04, d=0.39$; see Fig. 1 .

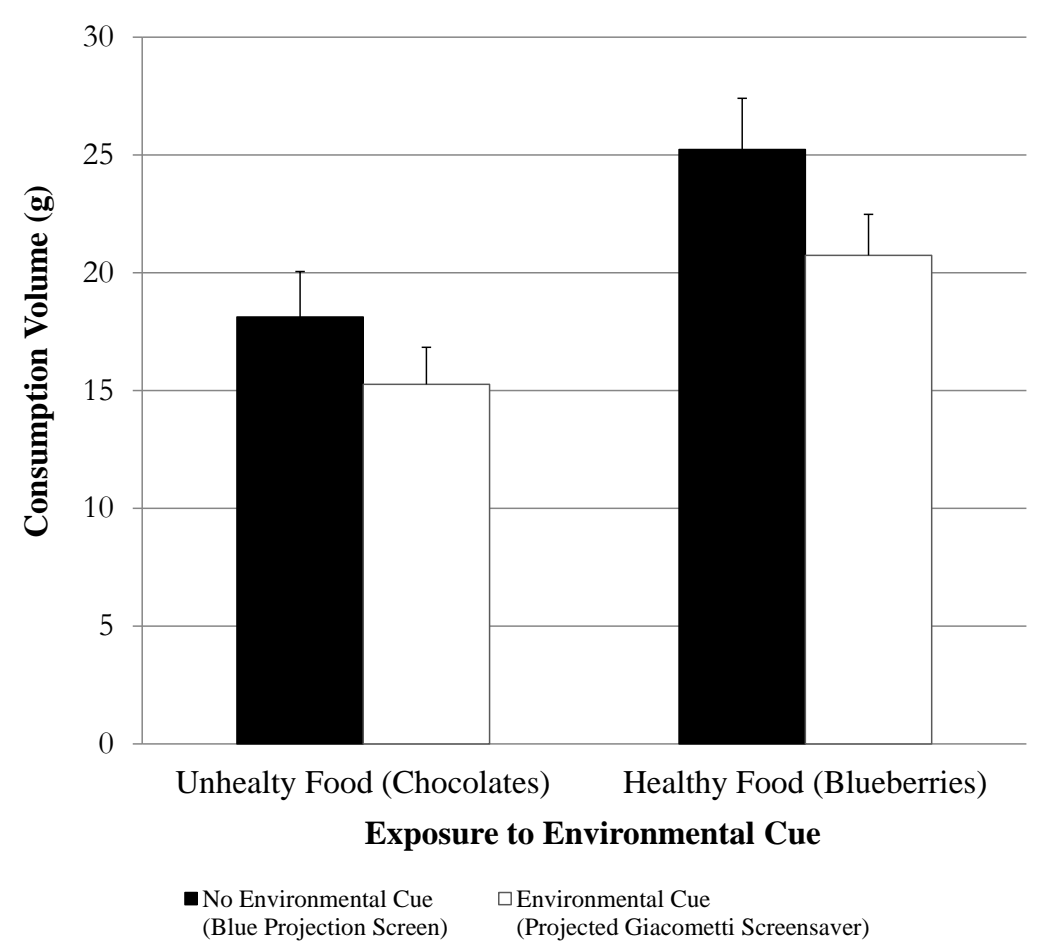

Figure 1. Mean consumption volume of chocolates and blueberries (in grams) for the four conditions (cue/no cue $\times$ unhealthy/healthy food). Participants exposed to a projected screensaver with thin Giacometti sculptures consumed less food than participants exposed to a neutral projection screen. Food healthiness did not alter this effect (error bars represent standard errors).

Importantly, food healthiness did not influence the Giacometti effect, $F(1,110)$ $=0.20, p=.66, \eta^{2}=.00$. Regarding the type of food, the ANOVA revealed a main effect of food healthiness, $F(1,110)=11.58, p<.01, \eta^{2}=.09$. Participants ate more of 
the healthy blueberries $(M=22.82$ grams, $S D=10.43)$ than they did of the unhealthy chocolates $(M=16.45$ grams, $S D=9.29), t(112)=3.45, p<.01, d=0.65$.

The influence of the Giacometti sculptures depends on restrained eating. Because food healthiness did not influence the Giacometti effect, food healthiness was omitted in the following analyses. The role that restrained eating plays in the Giacometti effect was analyzed using an ANCOVA that included the cue, restrained eating, and their interaction as independent variables. This analysis revealed that the effect depended on restrained eating, $F(1,109)=7.25, p=.01, \eta^{2}=.06$; main effect of the cue, $F(1,109)=3.42, p=.07, \eta^{2}=.03$, main effect of restrained eating, $F(1,109)=$ $0.16, p=.69, \eta^{2}=.00$. The Johnson-Neyman technique (Hayes, 2013) specified that the projected Giacometti screensaver influenced participants with a restrained eating score upwards of 3.15 on the 7-point scaled moderator variable restrained eating (with a significance level of $\alpha=.05$ ); see Fig. 2.

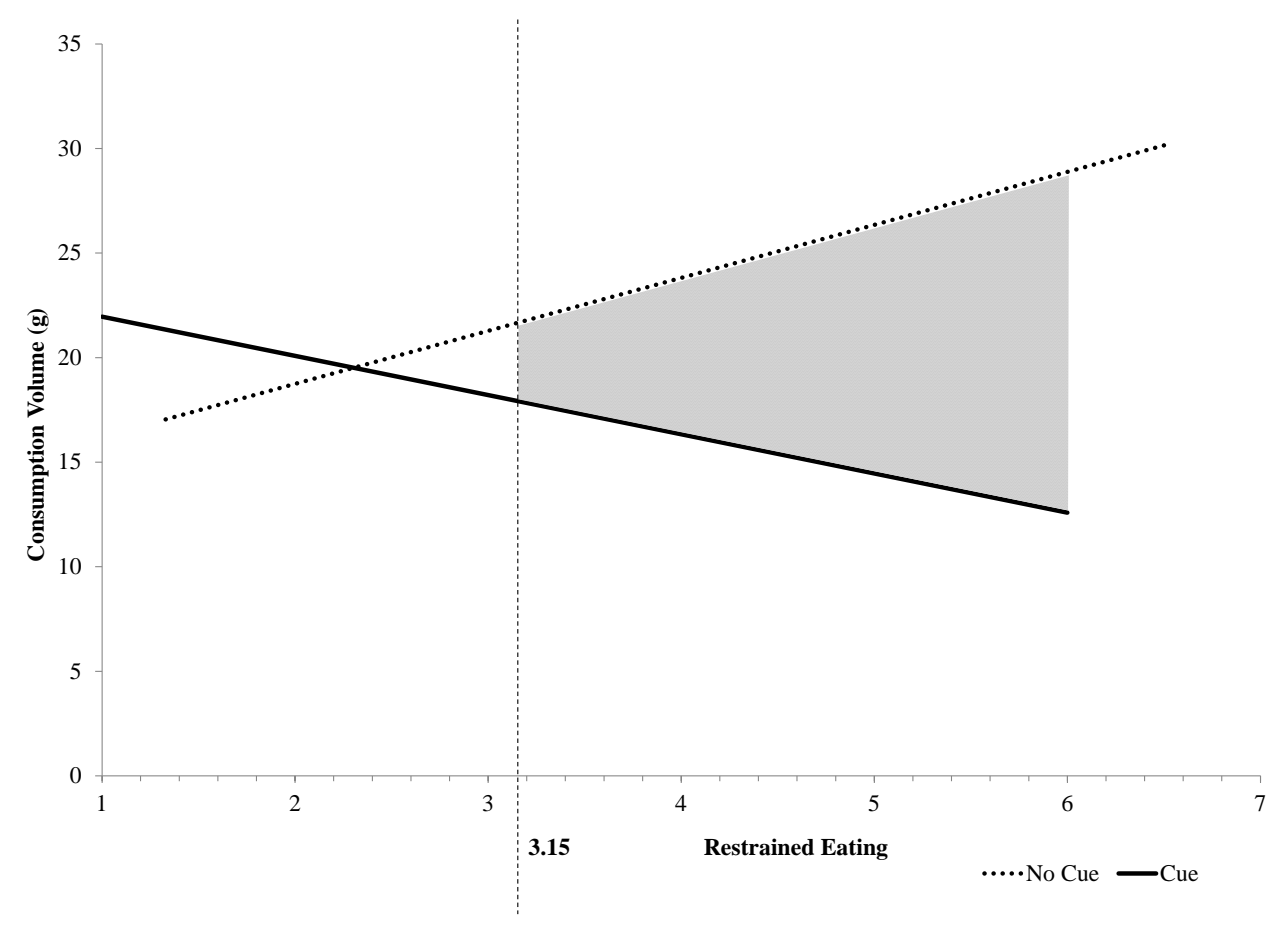

Figure 2. Chocolate or blueberry consumption as a function of restrained eating and exposure to an environmental cue. Exposure to a projected screensaver with Giacometti sculptures reduced the food intake of participants with a restrained eating score upwards of 3.15 . 
Analyses without exclusions. Because of the large number of excluded participants (19), all analyses were repeated without the exclusion of any participants at all. These analyses revealed a marginally significant Giacometti effect, $F(1,129)=$ $3.76, p=.06, \eta^{2}=.03$. The participants who had been exposed to the projected Giacometti screensaver ate by tendency less $(M=17.86$ grams, $S D=9.41)$ than the participants who had been exposed to the neutral blue projection screen $(M=21.10$ grams, $S D=10.58), t(131)=1.87, p=.06, d=0.32$. Food healthiness and the screensaver did not interact, $F(1,129)=0.04, p=.85, \eta^{2}=.00$. The main effect of food healthiness remained, $F(1,129)=16.12, p<.01, \eta^{2}=.11$. Participants ate more of the healthy blueberries $(M=22.65$ grams, $S D=10.00)$ than they did of the unhealthy chocolates $(M=16.04$ grams, $S D=9.03), t(131)=4.00, p<.01, d=0.69$. Importantly, restrained eating still moderated the Giacometti effect, $F(1,128)=7.25, p=.01, \eta^{2}=$ .05 ; main effect of the screensaver, $F(1,128)=3.62, p=.06, \eta^{2}=.03$, main effect of restrained eating, $F(1,128)=0.19, p=.66, \eta^{2}=.00$. The projected Giacometti screensaver influenced participants with a restrained eating score upwards of 3.16 (Hayes, 2013).

\section{Discussion}

The fact that the Giacometti cue's effect was independent of food healthiness in the analyses with and without participant exclusions reveals that the cue is weightrelated rather than health-related. While the cue's effect was only marginally significant in the analyses without exclusions, the Giacometti effect was found for restrained eaters in the analyses with and without participant exclusions. This indicates that the Giacometti effect is driven by a weight-control goal. 


\section{Study 2: The Influence of Thin Sculptures on the Completion of Weight- and Health-Related Fragmented Words}

To further analyze the mental content assumed to be activated by the Giacometti cue, Study 2 examined the content-related associations with the cue by means of a word completion task. In addition, the influence of weight- and health-related goals on the cue's effect on word completions was examined by analyzing the influence of restrained eating and general health interest.

\section{Method}

Participants. Participants from a campus other than the one where the first study was conducted were recruited in the university building. They were asked to take part in a study in exchange for a compensation of 10 Swiss Francs. In accordance with the place of recruitment, the sample consisted almost entirely of students.

Seventy-one individuals took part in the study. The data of 61 participants were used for the analyses $\left(M_{\text {age }}=23.53\right.$ years, $S D_{\text {age }}=5.07 ; 63.93 \%$ female $)$. One participant was excluded from the analyses because he was assumed to have seen the chocolates directly before the word completion task, and three participants were excluded because their German was insufficient. Another five were excluded because of a breakdown of their computer-based questionnaire. During the restart, these participants could have seen the video file named Giacometti. One more participant was excluded because he aborted his participation and therefore did not answer the question regarding whether he had heard of the study before and thus had a suspicion about the study's purpose.

Design. In this study, a one-factorial (cue vs. no cue) between-subjects design was applied to examine the cue's influence on how participants completed fragmented words in a word completion task. 


\section{Materials and measures.}

Measures. Fragmented words were created and pretested for their relatedness with weight or health (see Appendix, overview Appendix Table 1). Examples of the weight-related words are slim, dieting, and fat. Examples of the health-related words are apple, balanced, and fit. The dependent variable mentioning weight was the number of weight-related words mentioned in the word completion task. The dependent variable mentioning health was the number of health-related words mentioned in the word completion task. Very few of the words created by study participants had not been pretested. They were coded as weight- or health-related or neutral. They were also considered if they did not exactly match the gaps given in the fragmented words, since the associations with the sculptures were the focus of interest, not the correct completion of the fragmented words. The coding was done by two independent coders. In cases in which the coding results differed, the two coders reached agreement through discussion.

To examine the role of a weight-control goal in the Giacometti effect, Restrained eating ( $\alpha=.63$ ) was measured. As in Study 1, restrained eating was captured with the Concern for Dieting subscale (Dinkel et al., 2005). To operationalize a healthrelated goal, General health interest $(\alpha=.85)$ was captured. One item was not applied in the data collection because, by relating to cholesterol, it was considered too specific. Example items include the following: "The healthiness of food has little impact on my food choices"; "I always follow a healthy and balanced diet"; and "It is important for me that my daily diet contains a lot of vitamins and minerals" (Roininen, Lähteenmäki, $\&$ Tuorila, 1999). Both scales were captured on 7-point Likert scales $(1=\mathrm{I}$ do not agree at all; $7=$ I entirely agree). The question used to assess participants' suspicion about the study purpose was as follows: "Have you heard about this study and therefore have an 
idea of what the purpose of the study is?" The computer-based questionnaire was generated with E-Prime, version 2.0.10.353 (E-Prime 2 Professional).

\section{Procedure.}

The Giacometti cue (see Study 1) was presented as a screensaver directly on participants' computers before they started the computer-based questionnaire. In the nocue condition, the computers showed a static, white screen.

Participants chose a seat in a cubicle, and the experimenter explained the word completion task. While they were being seated and receiving oral instructions from the experimenter, participants were exposed to the screensavers for about 30 seconds. Then, they received the instruction to start the computer-based questionnaire by pressing a certain key on their keyboards. Participants first dealt with the word completion task. The fragmented words were displayed for 30 seconds in the same randomly ordered sequential selection for each participant. During this time, participants had time to enter the word that first came to mind. After the word completion task, participants completed the questionnaire by answering questions, including the items on restrained eating and general health interest.

\section{Results}

The Giacometti sculptures increased the weight-related word completion of restrained eaters. One-factor ANOVAs revealed no effect of the Giacometti screensaver on the amount of weight-related, $F(1,59)<0.01, p=.99, \eta^{2}=.00$, or health-related words created, $F(1,59)=0.71, p=.404, \eta^{2}=.01$. However, including restrained eating in an ANCOVA with mentioning weight as the dependent variable revealed an interaction of the screensaver with restrained eating, $F(1,57)=5.64, p=$ $.02, \eta^{2}=.09$; main effect of the screensaver, $F(1,57)=4.99, p=.03, \eta^{2}=.08$, main effect of restrained eating, $F(1,57)=0.58, p=.45, \eta^{2}=.01$. The Johnson-Neyman 
technique (Hayes, 2013) revealed that the Giacometti screensaver increased the creation of weight-related words in restrained eaters (in participants with a restrained eating score upwards of 4.03; with a significance level of $\alpha=.05$ ); see Fig. 3. In contrast, restrained eaters did not mention more health-related words after being exposed to the screensaver, $F(1,57)=0.07, p=.79, \eta^{2}=.00$; main effect of the screensaver, $F(1,57)=$ $0.00, p=.96, \eta^{2}=.00$, main effect of restrained eating, $F(1,57)=0.57, p=.45, \eta^{2}=$ .01 .

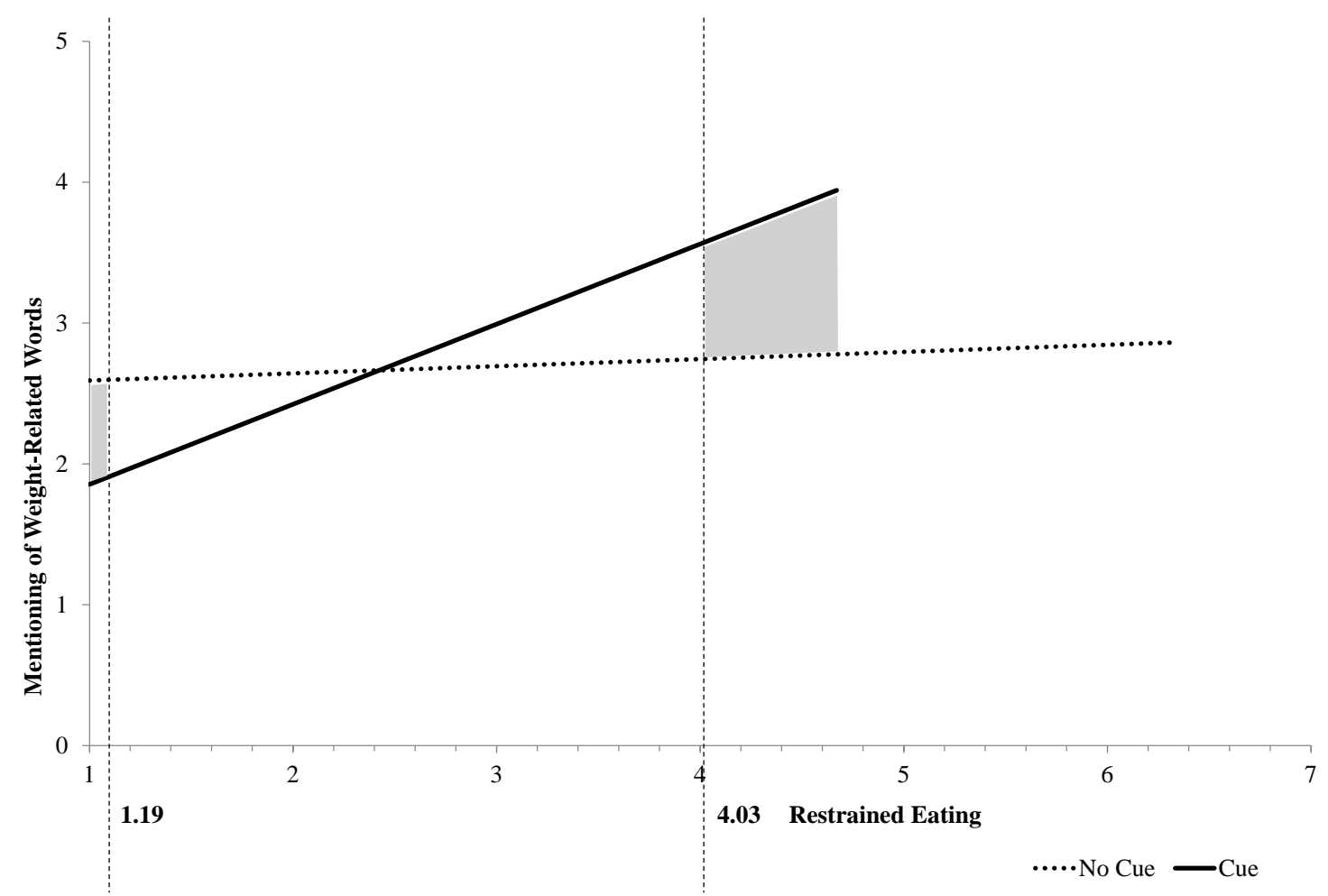

Figure 3. Creation of weight-related words as a function of restrained eating and exposure to an environmental cue. A screensaver with thin, human-like sculptures increased the creation of weight-related words in a word completion task in restrained eaters (upwards of a restrained eating score of 4.03. The effect was reversed for highly unrestrained eaters with a restrained eating score below 1.19).

An ANCOVA including the cue, general health interest, and their interaction as independent variables and the number of health-related words created as dependent variables revealed no interaction of the screensaver with general health interest, $F(1,57)$ 
$=0.51, p=.48, \eta^{2}=.01 ;$ main effect of the screensaver, $F(1,57)=0.26, p=.61, \eta^{2}=$ .00 , main effect of general health interest, $F(1,57)=1.75, p=.19, \eta^{2}=.03$.

Correlations of mentioned weight- and health-related words. In order to explore the effects of the activated weight-related content on health-related content, we examined the possible changes in the association of mental weight- and health-related content as a consequence of the cue exposure. Bivariate correlation analyses were conducted. They revealed that the participants' mentioning of health- and weight-related words did not correlate, both in participants exposed to the neutral screensaver, $r_{\text {Spearman }}$ $(29)=.33, p=.08$, and in participants exposed to the Giacometti screensaver, $r_{\text {Spearman }}$ $(32)=.11, p=.54$. In addition, the association of weight- and health-related words mentioned, measured with the difference of health-mentioning and weight-mentioning, did not differ between the neutral condition $(M=1.90, S D=1.70)$ and the cue condition $(M=2.28, S D=2.05), t(59)=.79, p=.43, d=0.20$. An ANCOVA analyzing the effects of the cue, restrained eating, and the interaction of cue and restrained eating on the difference of weight- and health-related words mentioned revealed that the association of weight- and health-related words mentioned between the cue and the nocue condition did not depend on restrained eating, $F(1,57)=1.76, p=.19, \eta^{2}=.03$; main effect of the screensaver, $F(1,57)=2.08, p=.15, \eta^{2}=.02$, main effect of restrained eating, $F(1,57)=1.49, p=.23, \eta^{2}=.03$. These results indicate that weightand health-related content did not correlate in our sample and that this did not change with either cue exposure or cue exposure and restrained eating.

Analyses without exclusions. No significant results were found when all of the analyses were conducted without any exclusion of participants. One-factor ANOVAs revealed no effect of the screensaver on the number of weight-related, $F(1,69)=0.51, p$ $=.48, \eta 2=.00$, or health-related words created, $F(1,69)=0.52, p=.48, \eta 2=.01$. 
Analyzing the data with an ANCOVA that included restrained eating did not yield any relationships. There was no interaction of the screensaver with restrained eating, $F(1$, $66)=0.08, p=.78, \eta 2=.00$, a main effect of the screensaver, $F(1,66)=0.01, p=.93$, $\eta 2=.00$, or a main effect of restrained eating, $F(1,66)=0.86, p=.36, \eta 2=.01$. An ANCOVA including the cue, general health interest, and their interaction as independent variables and the number of health-related words created as dependent variables revealed no interaction of the screensaver with general health interest, $F(1,66)$ $=.48, p=.01, \eta^{2}=.01 ;$ main effect of the screensaver, $F(1,66)=.61, p<.01, \eta^{2}=.00$, main effect of general health interest, $F(1,66)=.16, p=.16, \eta^{2}=.03$.

No indications of a difference in the association of weight- and health-related words mentioned as a consequence of the cue exposure or the cue exposure and restrained eating were found for the sample without participant exclusions.

\section{Discussion}

The results of the analyses with participant exclusions in Study 2 are in line with the results of Study 1. With restrained eaters' increased mentioning of weight-related words after they were exposed to the thin Giacometti sculptures, Study 2 indicates that the Giacometti cue is weight-related and that the Giacometti effect is driven by a weight-control goal. However, because the activation of weight-related words by the Giacometti cue for restrained eaters could not be found in the sample without participant exclusions, no firm conclusion should be drawn from these results. In contrast, calculated with and without participant exclusions, the cue had no influence on the mentioning of health-related words, even in individuals with a relatively high general health interest. The results of the correlation analyses indicate that weight- and health-related content did not correlate in our sample. 


\section{General Discussion}

The present paper aimed to shed light on the content-related processes underlying priming effects with a distinct environmental cue - thin, human-like sculptures by the artist Alberto Giacometti . This is because content-related cognitive processes mostly have been neglected in existing priming studies using environmental cues (Bargh, 2006; Papies \& Veling, 2013). In our studies, the Giacometti sculptures were found to be a weight-related environmental cue that can help restrained eaters in facilitating their dieting by reducing their consumption volume.

\section{Priming Weight is not Priming Health}

A detailed understanding of the specific mental content activated by an environmental cue provides the first indications with respect to a cue's possible use. Such understanding also indicates which individuals could be addressed with a distinct cue-i.e., individuals who have a goal that the cue can activate.

However, when an environmental cue, such as the Giacometti sculptures, has an effect on weight-related content, it is conceivable that health-related content is also activated (Janiszewski \& Wyer, 2014). This is because weight and health are commonly thought to be semantically related. This could not be shown in our sample, however, and health-related content was not activated by the Giacometti sculptures. One potential reason why a relationship could not be determined between weight- and health-related content may be the young age of the participants in Study 2. Health problems caused by weight may not yet be manifest in youth. Nonetheless, being overweight has negative health consequences (World Health Organization, 2002).

\section{Implications}

In regard to the prevailing epidemic of overweight and obesity (World Health Organization, 2016), environmental dieting cues can play a pivotal role. Primary 
weight-related cues can be seen as counterparts to the abundance of food and foodrelated cues in our obesogenic environment (Papies et al., 2014).

An example of applied environmental cues for the promotion of health is the deterrent pictures on cigarette packages, which show the physical consequences of smoking (European Union, 2014). However, studies have found these deterrent pictures to be ineffective (Glock \& Kneer, 2009). This indicates that obese figures and the "fear of fat" (Anschutz, Engels, Becker, \& van Strien, 2009) would be less effective drivers against eating high-calorie food than cues such as the thin Giacometti sculptures. These sculptures can be seen as motivators, as they emphasize the positive consequences of eating less high-calorie food in order to get closer to the ideal of a thin figure (van de Veer et al., 2015). Results from neural research substantiate that motivation works better than deterrence in the domain of eating. Besides homeostatic regulation, eating is assumed to be controlled by a neural network, which is supposed to consist of a reward pathway and a control pathway (Chen, Papies, \& Barsalou, 2016). Interestingly, thinking about the long-term benefits of not eating has been found to increase activity in the inhibitory neural pathway and to reduce activity in the reward pathway more than thinking about the long-term costs of eating (Yokum \& Stice, 2013). Evidence from research on reactions to thin and round figures further indicates that thin figures may have more influence on reducing calorie intake than obese figures. For example, dieters ate less when their server was thin than when she was overweight (McFerran, Dahl, Fitzsimons, \& Morales, 2010).

With regard to the specific body forms of the Giacometti sculptures, it must be acknowledged that human bodies with figures similar to these sculptures would be seriously underweight. Thus, they would be perceived as less attractive and thus less motivating than figures corresponding to the lower ranges of normal body mass indices 
(Tovée, Edmonds, \& Vuong, 2012; Tovée, Furnham, \& Swami, 2007; Weeden \& Sabini, 2005). When using human models as environmental cues, using healthier-looking human figures could thus work better than skinny human figures. Supporting evidence for this demonstrates that female television viewers ate less unhealthy food when they watched average-sized or slightly oversized models than they did when exposed to thin models (Anschutz et al., 2009). However, when compared to using human models as environmental cues, the Giacometti sculptures seem to have the advantage of being more generally applicable. Social comparison processes due to characteristics such as clothing or age should be prevented when using artistically simplified human sculptures (Corcoran, Crusius, \& Mussweiler, 2011).

\section{Limitations}

Besides the conceivable application of environmental cues for public policy purposes, the question arises whether dieting cues could be used intentionally by individuals for losing weight. If applied intentionally, a cue could be processed more controlled than when used as a subtle prime. There is evidence that intention could even support a cue's influence, as primes can affect behavior through both automatic and controlled processes (Payne, Brown-Iannuzzi, \& Loersch, 2016). Because losing weight is a long-term process, another question that arises is what would happen if cues are applied repeatedly. To our knowledge, there is very little evidence revealing the effects of repeatedly exposing individuals to an environmental weight- or health-related cue (Klesse, Goukens, Geyskens, \& Ruyter, 2012). A constant reactivation of goals and a habituation to the cue with a decreasing effect of the cue (Rankin et al., 2009) are both conceivable.

With a long-term application of environmental weight-control cues, the unintended effects of exposing people to the thin ideal become more important and have 
to be taken into consideration. Examples of unintended effects are negative affect, increased body dissatisfaction, and disordered eating patterns for vulnerable groups of people, such as vulnerable adolescents (Stice, Spangler, \& Agras, 2001) or unsuccessful restrained eaters (Schaumberg, Anderson, Anderson, Reilly, \& Gorrell, 2016).

\section{Conclusion}

In sum, the present research indicates that exposure to thin, human-like sculptures by the artist Alberto Giacometti reduces food intake in restrained eaters and thus that the Giacometti effect is driven by a weight-control goal. Given that restrained eaters are often unsuccessful in dieting (Lowe et al., 2013; Stroebe et al., 2008), partly because of the obesogenic environment with its abundance of food and food-related cues (Lowe et al., 2013; Papies et al., 2014; Stroebe et al., 2008), dieting cues in the environment can be seen as helpful counterparts. By helping restrained eaters to pursue their weight-control goal, environmental weight-control cues could act as daily nudges in a healthier direction (Hill, Wyatt, Reed, \& Peters, 2003). 


\section{References}

Aarts, H. (2007). Health and goal-directed behavior: The nonconscious regulation and motivation of goals and their pursuit. Health Psychology Review, 1(1), 53-82. doi:10.1080/17437190701485852

Aarts, H., \& Dijksterhuis, A. (2003). The silence of the library: Environment, situational norm, and social behavior. Journal of Personality and Social Psychology, 84(1), 1828. doi:10.1037/0022-3514.84.1.18

Anschutz, D. J., Engels, R. C., Becker, E. S., \& van Strien, T. (2009). The effects of TV commercials using less thin models on young women's mood, body image and actual food intake. Body Image, 6(4), 270-276. doi:10.1016/j.bodyim.2009.07.007

Anschutz, D. J., van Strien, T., \& Engels, R. C. (2008). Exposure to slim images in mass media: Television commercials as reminders of restriction in restrained eaters. Health Psychology, 27(4), 401-408. doi:10.1037/0278-6133.27.4.401

Bargh, J. A. (2006). What have we been priming all these years? On the development, mechanisms, and ecology of nonconscious social behavior. European Journal of Social Psychology, 36(2), 147-168. doi:10.1002/ejsp.336

Bargh, J. A., Gollwitzer, P. M., Lee-Chai, A., Barndollar, K., \& Trötschel, R. (2001). The automated will: Nonconscious activation and pursuit of behavioral goals. Journal of Personality and Social Psychology, 81(6), 1014-1027. doi:10.1037//00223514.81.6.1014

Berthoud, H.-R. (2006). Homeostatic and non-homeostatic pathways involved in the control of food intake and energy balance. Obesity, 14, 197S-200s. doi:10.1038/oby.2006.308

Brunner, T. A., \& Siegrist, M. (2012). Reduced food intake after exposure to subtle weight-related cues. Appetite, 58(3), 1109-1112. doi:10.1016/j.appet.2012.03.010 
Cancer League (2016). 5 a day. Retrieved from https://www.5amtag.ch/en/

Chartrand, T. L. (2005). The role of conscious awareness in consumer behavior. Journal of Consumer Psychology, 15(3), 203-210. doi:10.1207/s15327663jcp1503_4

Chen, J., Papies, E. K., \& Barsalou, L. W. (2016). A core eating network and its modulations underlie diverse eating phenomena. Brain and Cognition, (16), S02782626. doi: 10.1016/j.bandc.2016.04.004

Corcoran, K, Crusius, J., \& Mussweiler, T. (2011). Social comparisons. Motives, standards, and mechanisms. In D. Chadee (Ed.), Theories in social psychology (pp. 119-139). Malden, MA: Wiley-Blackwell.

Custers, R., \& Aarts, H. (2005). Positive affect as implicit motivator: On the nonconscious operation of behavioral goals. Journal of Personality and Social Psychology, 89(2), 129-142. doi:10.1037/0022-3514.89.2.129

Dinkel, A., Berth, H., Exner, C., Rief, W., \& Balck, F. (2005). Deutsche Adaptation der Restraint Scale zur Erfassung gezügelten Essverhaltens. Diagnostica, 51(2), 67-74. doi:10.1026/0012-1924.51.2.67

European Union (2014). Directive 2014/40/EU of the European parliament and of the council of 3 April 2014 on the approximation of the laws, regulations and administrative provisions of the member states concerning the manufacture, presentation and sale of tobacco and related products and repealing Directive 2001/37/EC. Retrieved from http://ec.europa.eu/health/tobacco/docs/ dir_201440_en.pdf

E-Prime 2 Professional (version 2.0.10.353) [Computer software]. Sharpsburg, PA: Psychology Software Tools. 
Fedoroff, I., Polivy, J., \& Herman, C. P. (2003). The specificity of restrained versus unrestrained eaters' responses to food cues: General desire to eat, or craving for the cued food? Appetite, 41(1), 7-13. doi:10.1016/S0195-6663(03)00026-6

Fedoroff, I., Polivy, J., \& Herman, C. P. (1997). The effect of pre-exposure to food cues on the eating behavior of restrained and unrestrained eaters. Appetite, 28(1), 33-47. doi:10.1006/appe.1996.0057

Glock, S., \& Kneer, J. (2009). Are deterrent pictures effective? The impact of warning labels on cognitive dissonance in smokers. Applied Psychology: Health and WellBeing, 1(3), 356-373. doi:10.1111/j.1758-0854.2009.01019.x

Harris, J. L., Bargh, J. A., \& Brownell, K. D. (2009). Priming effects of television food advertising on eating behavior. Health Psychology, 28(4), 404-413. doi:10.1037/a0014399

Hayes, A. F. (2013). Introduction to mediation, moderation, and conditional process analysis: A regression-based approach. New York: Guilford Press.

Herman, C. P., \& Mack, D. (1975). Restrained and unrestrained eating. Journal of Personality, 43(4), 647-660. doi:10.1111/j.1467-6494.1975.tb00727.x

Herman, C. P., \& Polivy, J. (1980). Restrained eating. In A. J. Stunkard (Ed.), Obesity (pp. 208-225). Philadelphia/London/Toronto: W. B. Saunders Company.

Hill, J. O., Wyatt, H. R., Reed, G. W., \& Peters, J. C. (2003). Obesity and the environment: Where do we go from here? Science, 299, 853-855. doi:10.1126/science.1079857

Hofmann, W., van Koningsbruggen, G. M., Stroebe, W., Ramanathan, S., \& Aarts, H. (2010). As pleasure unfolds: Hedonic responses to tempting food. Psychological Science, 21(12), 1863-1870. doi:10.1177/0956797610389186 
Janiszewski, C., \& Wyer, R. S. (2014). Content and process priming: A review. Journal of Consumer Psychology, 24(1), 96-118. doi:10.1016/j.jcps.2013.05.006

Jones, L. L., \& Estes, Z. (2012). Lexical priming: Associative, semantic and thematic influences on word recognition. In J. S. Adelman (Ed.), Visual Word Recognition, (Vol. 2). Hove, UK: Psychology Press.

Klesse, A. K., Goukens, C., Geyskens, K., \& de Ruyter, K. (2012). Repeated exposure to the thin ideal and implications for the self: Two weight loss program studies. International Journal of Research in Marketing, 29, 355-362. doi: /10.1016/j.ijresmar.2012.06.003

Lowe, M. R., Doshi, S. D., Katterman, S. N., \& Feig, E. H. (2013). Dieting and restrained eating as prospective predictors of weight gain. Frontiers in Psychology, 4, 1-7. doi:10.3389/fpsyg.2013.00577

McFerran, B., Dahl, D. W., Fitzsimons, G. J., \& Morales, A. C. (2010). Might an overweight waitress make you eat more? How the body type of others is sufficient to alter our food consumption. Journal of Consumer Psychology, 20(2), 146-151. doi:10.1016/j.jcps.2010.03.006

Papies, E. K. (2016). Goal priming as a situated intervention tool. Current Opinion in Psychology, 12, 12-16. doi:10.1016/j.copsyc.2016.04.008

Papies, E. K., \& Hamstra, P. (2010). Goal priming and eating behavior: Enhancing selfregulation by environmental cues. Health Psychology, 29, 384-388. doi:10.1037/a0019877

Papies, E. K., Potjes, I., Keesman, M., Schwinghammer, S., \& van Koningsbruggen, G. M. (2014). Using health primes to reduce unhealthy snack purchases among overweight consumers in a grocery store. International Journal of Obesity, 38(4), 597-602. doi:10.1038/ijo.2013.136 
Papies, E. K., Stroebe, W., \& Aarts, H. (2008). The allure of forbidden food: On the role of attention in self-regulation. Journal of Experimental Social Psychology, 44(5), 1283-1292. doi:10.1016/j.jesp.2008.04.008

Papies, E. K., \& Veling, H. (2013). Healthy dining. Subtle diet reminders at the point of purchase increase low-calorie food choices among both chronic and current dieters. Appetite, 61, 1-7. doi:10.1016/j.appet.2012.10.025

Payne, B. K., Brown-Iannuzzi, J. L., \& Loersch, C. (2016). Replicable effects of primes on human behavior. Journal of Experimental Psychology. General, 145(10), 12691279. doi:10.1037/xge0000201

Rankin, C. H., Abrams, T., Barry, R. J., Bhatnagar, S., Clayton, D. F., Colombo, J., . . . Thompson, R. F. (2009). Habituation revisited: An updated and revised description of the behavioral characteristics of habituation. Neurobiology of Learning and Memory, 92(2), 135-138. doi:10.1016/j.nlm.2008.09.012

Renner, B., Sproesser, G., Strohbach, S., \& Schupp, H. T. (2012). Why we eat what we eat. The Eating Motivation Survey (TEMS). Appetite, 59(1), 117-128. doi:10.1016/j.appet.2012.04.004

Roininen, K., Lähteenmäki, L., \& Tuorila, H. (1999). Quantification of consumer attitudes to health and hedonic characteristics of foods, Appetite, 33, 71-88. doi: 10.1006/appe.1999.0232

Schaumberg, K., Anderson, D. A., Anderson, L. M., Reilly, E. E., \& Gorrell, S. (2016). Dietary restraint: what's the harm? A review of the relationship between dietary restraint, weight trajectory and the development of eating pathology. Clinical Obesity, 6(2), 89-100. doi:10.1111/cob.12134 
Shah, J. Y., Friedman, R., \& Kruglanski, A. W. (2002). Forgetting all else: On the antecedents and consequences of goal shielding. Journal of Personality and Social Psychology, 83(6), 1261-1280. doi:10.1037//0022-3514.83.6.1261

Snoek, H. M., Engels, R. C., van Strien, T., \& Otten, R. (2013). Emotional, external and restrained eating behaviour and BMI trajectories in adolescence. Appetite, 67, 81-87. doi:10.1016/j.appet.2013.03.014

Soetens, B., Roets, A., \& Raes, F. (2014). "Food for memory": Pictorial food-related memory bias and the role of thought suppression in high and low restrained eaters. The Psychological Record, 64(1), 105-114. doi:10.1007/s40732-014-0016-0

Stice, E., Spangler, D., \& Agras, W. S. (2001). Exposure to media-portrayed thin-ideal images adversely affects vulnerable girls: A longitudinal experiment. Journal of Social and Clinical Psychology, 20(3), 270-288. doi: 10.1521/jscp.20.3.270.22309

Stämpfli, A. E., \& Brunner, T. A. (2016). The art of dieting: Exposure to thin sculptures effortlessly reduces the intake of unhealthy food in motivated eaters. Food Quality and Preference, 50, 88-93. doi:10.1016/j.foodqual.2016.01.012

Stöckli, S., Stämpfli, A. E., Messner, C., \& Brunner, T. A. (2016). An (un)healthy poster: When environmental cues affect consumers' food choices at vending machines. Appetite, 96, 368-374. doi:10.1016/j.appet.2015.09.034

Stroebe, W., Mensink, W., Aarts, H., Schut, H., \& Kruglanski, A. W. (2008). Why dieters fail: Testing the goal conflict model of eating. Journal of Experimental Social Psychology, 44(1), 26-36. doi:10.1016/j.jesp.2007.01.005

Stroebe, W., van Koningsbruggen, G. M., Papies, E. K., \& Aarts, H. (2012). Why most dieters fail but some succeed: A goal conflict model of eating behavior. Psychological Review, 120(1), 110-138. doi:10.1037/a0030849 
Thaler, R. H., \& Sunstein, C. R. (2009). Nudge: Improving decisions about health, wealth, and happiness (revised and expanded ed.). London, England: Penguin Books.

Tovée, M. J., Edmonds, L., \& Vuong, Q. C. (2012). Categorical perception of human female physical attractiveness and health. Evolution and Human Behavior, 33(2), 85-93. doi:10.1016/j.evolhumbehav.2011.05.008

Tovée, M. J., Furnham, A., \& Swami, V. (2007). Healthy body equals beautiful body? Changing perceptions of health and attractiveness with shifting socioeconomic status. Basingstoke, Hampshire, England: Palgrave Macmillan.

Van de Veer, E., van Herpen, E., \& van Trijp, H. C. (2015). How do I look? Focusing attention on the outside body reduces responsiveness to internal signals in food intake. Journal of Experimental Social Psychology, 56, 207-213. doi:10.1016/j.jesp.2014.10.003

van Koningsbruggen, G. M., Stroebe, W., \& Aarts, H. (2011). Through the eyes of dieters: Biased size perception of food following tempting food primes. Journal of Experimental Social Psychology, 47(2), 293-299. doi:10.1016/j.jesp.2010.10.012 van Strien, T., Breteler, M. H., \& Ouwens, M. A. (2002). Restraint Scale, its sub-scales concern for dieting and weight fluctuation. Personality and Individual Differences, 33(5), 791-802. doi:10.1016/S0191-8869(01)00192-1

Versluis, I., \& Papies, E. K. (2016). Eating less from bigger packs: Preventing the pack size effect with diet primes. Appetite, 100, 70-79. doi:10.1016/j.appet.2016.02.011

Weeden, J., \& Sabini, J. (2005). Physical attractiveness and health in Western societies: A review. Psychological Bulletin, 131(5), 635-653. doi:10.1037/00332909.131.5.635 
World Health Organization (2002). The world health report. Retrieved from http://www.who.int/whr/2002/en/whr02_en.pdf?ua=1

World Health Organization (2004). Global strategy on diet, physical activity and health. Retrieved from http://www.who.int/dietphysicalactivity/strategy/eb11344/ strategy_english_web.pdf

World Health Organization (2016). Nutrition: Controlling the global obesity epidemic. Retrieved from http://www.who.int/nutrition/topics/obesity/en/

Yokum, S., \& Stice, E. (2013). Cognitive regulation of food craving: Effects of three cognitive reappraisal strategies on neural response to palatable foods. International Journal of Obesity, 37(12), 1565-1570. doi:10.1038/ijo.2013.39 


\section{Appendix}

\section{Pretest Fragmented Words}

To assess whether the Giacometti screensaver activates health- or weight-related mental content, 40 fragmented words were created: 20 that could be completed either by a weight-related or a neutral word and 20 that could be completed either by a healthrelated or a neutral word. Efforts were made to ensure that the words were not too difficult to complete. A qualitative pretest with 14 individuals (57\% female) ensured this and also assessed how often the fragmented words were completed by a weight- or health-related (i.e., semantic category-related) word instead of a neutral word. Ten fragmented words were chosen per semantic category. Between $7 \%$ and $57 \%$ were completed with a category-related word. With this choice, a sufficient variance was expected in semantic category-related and neutral word completions per fragmented word. The expected weight-related words included, e.g., slim, dieting, and fat. The expected health-related words included, e.g., apple, balanced, and fit.

A second independent pretest was conducted to examine whether the words conceived to represent the weight- and health-related semantic categories can be assigned distinctly to weight or health. One hundred and forty-eight individuals participated in an online questionnaire. The link to this questionnaire was posted in online market places of university websites. The data of everyone who completed the questionnaire (117 participants) were analyzed. In a first step, the participants had to rate how strongly they associated the envisaged weight- and health-related words with both weight and health $(0=$ not at all; $5=$ strongly $)$. They associated all semantic category words with the expected semantic category. All words had a mean rating of higher than 3, which was higher than the mean of the competing semantic category, with two exceptions. The words eating and sugar, which were created to represent the weight 
category, were associated only in tendency more strongly with weight than with health (see Table 1). In a second step of this pretest, participants had to decide the category with which they associated each word the most: weight, health, or neither of these categories. Binomial tests revealed that all assignments were made as expected except for the words eating, sugar, and fasting, which were envisaged to represent the weight category. While sugar $(p=.34)$ and fasting $(p=.18)$ were assigned in tendency to weight, eating was assigned, in contrast to our expectation, in tendency to health $(p=$ .40 ; see Table 1). As a consequence, the word eating was dropped. 
APPENDIX

Table 1

A Pretest Reveals the Words Used to Measure Weight-and Health-Related Words Mentioned, the Dependent Variables of Study $2 . \quad N=117$

\begin{tabular}{|c|c|c|c|c|c|c|c|c|}
\hline & & \multicolumn{3}{|c|}{$\begin{array}{l}\text { "Please indicate how strongly you associate the } \\
\text { word } x \text { with the categories weight and health." } \\
(0=\text { not at all; } 5=\text { strongly })\end{array}$} & \multicolumn{3}{|c|}{$\begin{array}{l}\text { "Now you have to tie yourself down: With which } \\
\text { of those categories (weight, health, neither) do you } \\
\text { associate the following words the most?" }\end{array}$} & \multirow[b]{2}{*}{$p$} \\
\hline \multicolumn{2}{|c|}{ Words envisaged } & $M_{\text {weight }}(S D)$ & $M_{\text {health }}(S D)$ & $p$ & Weight & Health & Neither & \\
\hline \multirow[t]{9}{*}{ Weight-related words ${ }^{a}$} & eating $^{\mathrm{b}}$ & $4.32(1.11)$ & $4.23(1.12)$ & 31 & 53 & 63 & 1 & \\
\hline & slim & $4.50(1.02)$ & $3.54(1.19)$ & $<.01$ & 101 & 13 & 3 & $<.01$ \\
\hline & belly & $3.83(1.19)$ & $2.91(1.52)$ & $<.01$ & 87 & 23 & 7 & $<.01$ \\
\hline & fasting & $3.83(1.27)$ & $3.43(1.43)$ & .01 & 62 & 47 & 8 & \\
\hline & skinny & $4.13(1.29)$ & $3.38(1.51)$ & $<.01$ & 95 & 19 & 3 & $<.01$ \\
\hline & kilo & $4.71(0.83)$ & $2.67(1.52)$ & $<.01$ & 112 & 1 & 4 & $<.01$ \\
\hline & sugar & $3.97(1.30)$ & $3.91(1.28)$ & & 60 & 49 & 8 & \\
\hline & dieting & $4.70(0.80)$ & $3.42(1.32)$ & $<.01$ & 108 & 7 & 2 & $<.01$ \\
\hline & fat & $4.74(0.67)$ & $3.91(1.33)$ & $<.01$ & 108 & 8 & 1 & $<.01$ \\
\hline \multirow[t]{9}{*}{ Health-related words } & movement & $4.19(1.13)$ & $4.73(0.54)$ & $<.01$ & 12 & 104 & 1 & $<.01$ \\
\hline & strong & $2.75(1.44)$ & $3.19(1.35)$ & $<.01$ & 33 & 64 & 20 & $<.01$ \\
\hline & lively & 2.08 (1.66) & $3.79(1.38)$ & $<.01$ & 2 & 105 & 10 & $<.01$ \\
\hline & apple & $2.38(1.55)$ & $3.85(1.32)$ & $<.01$ & 8 & 98 & 11 & $<.01$ \\
\hline & active & $3.74(1.34)$ & $4.36(0.85)$ & $<.01$ & 10 & 103 & 4 & $<.01$ \\
\hline & fruits & $3.15(1.34)$ & $4.51(0.82)$ & $<.01$ & 8 & 105 & 4 & $<.01$ \\
\hline & balanced & $3.44(1.36)$ & $4.10(1.17)$ & $<.01$ & 12 & 103 & 2 & $<.01$ \\
\hline & fit & $3.79(1.20)$ & $4.50(0.81)$ & $<.01$ & 14 & 102 & 1 & $<.01$ \\
\hline & well & $2.78(1.70)$ & $3.83(1.35)$ & $<.01$ & 8 & 102 & 7 & $<.01$ \\
\hline
\end{tabular}

Notes:

${ }^{a}$ The words are translated from German except light, which is also used in German.

${ }^{\mathrm{b}}$ Because eating was, in contrast to our expectation, assigned (in tendency) to health, it was dropped for the measurement of weight-related words in Study 2. 